\title{
Bioadhesive Garlic and Ketoconazole Vaginal Tablets for Treatment of Candidiasis
}

\author{
Trupti Ashok Powar ${ }^{1}$, Ashok Ananda Hajare ${ }^{1 *}$, Preeti Bhimashankar Patil-Vibhute ${ }^{1}$, Sameer Jahangeer \\ Nadaf $^{2}$, Ravindra Jagannath Jarag ${ }^{1}$
}

1Department of Pharmaceutics, Bharati Vidyapeeth College of Pharmacy, Near Chitranagari, Kolhapur 416013 Maharashtra, INDIA. 2Department of Pharmaceutics, Adarsh College of Pharmacy, Bhavani Nagar, Vita, 415311 Maharashtra, INDIA.

\begin{abstract}
Objective: The study represents design and development of a combination type of bioadhesive vaginal tablets of garlic and ketoconazole by direct compression for enhanced antifungal effect. Material and methods: In these, work ketoconazole tablets, garlic tablets, and garlic and ketoconazole combination tablets were prepared using $3^{2}$ factorial design. HPMC K15M, chitosan, and microcrystalline cellulose were employed as bioadhesive polymers whereas, sodium bicarbonate and citric acid were incorporated to exert effervescence. Tablets were evaluated for swelling, bioadhesion and in-vitro drug release as dependent variables. The comparative in-vitro antifungal effects of optimized formulations were made with commercial tablets. Results: All tablet formulations exhibited sustained effect with moderate bio-adhesion characteristics. A tablet containing garlic: ketoconazole at $2: 1.5$ showed significant $(p<0.05)$ in-vitro antifungal activity compared to reference tablet. Ex-vivo mucoadhesion times of formulations were ranged from 8 - $15 \mathrm{~h}$. Enhanced antifungal activity is the result of the synergistic effect exerted by garlic with ketoconazole, as both are highly stable and soluble at $\mathrm{pH} 5$. The synergistic effect produced by garlic with ketoconazole was proved by molecular docking studies, used to determine virtual interactions between them. Conclusion: The resulting outcome indicates that combination of the synthetic drug with natural actives could enhance the antifungal activity with a simultaneous reduction in drug dosage and side or toxic effects providing a potential tablet formulation to treat vaginal candidiasis.
\end{abstract}

Key words: Ketoconazole, Garlic, Bioadhesion, Vaginal candidiasis, Molecular docking.

\section{INTRODUCTION}

Advanced pharmaceutical tablet formulation designs are used to overcome limitations of conventional tablets. One of the design is bioadhesive sustained release vaginal tablet used for the treatment of topical and systemic diseases. The vaginal route is important for drug delivery but is relatively unexplored despite its potential non-invasive route of drug administration. The presence of denser blood network renders vagina as an excellent route for delivery of drug to exert systemic and local effects. The major advantages of this route are by passing first pass metabolism, high permeability for low molecular weight drugs and ease of administration. Such dosage forms have the great advantage of maintaining the drug in the vagina for an extended period of time, including day and night times, thereby enabling lower dosing frequencies. Traditionally, solutions, suppositories, gels, foams, and tablets have been used as vaginal formulations. ${ }^{1}$ Recent studies include the use of the vaginal ring for hormone replacement and contraceptive therapy. Nowadays vaginal formulations are designed to produce local effects like spermicide or antibacterial and a systemic effect by continuous release of drugs such as contraceptives. ${ }^{2}$ Conventional vaginal formulations are associated with limitation of the minimum retention to the vaginal epithelium, leakage and
Submission Date: 30-08-2016; Revision Date: 17-11-2016; Accepted Date: 23-11-2016

DOI: 10.5530/ijper.51.2.29 Correspondence: Ashok A. Hajare, Department of Pharmaceutical Technology,

Bharati Vidyapeeth College of Pharmacy, Kolhapur, Maharashtra, India-416013 Tel. (0231) 2637286, Mobile - 9823695030 , Fax: (0231) 2638833 E-mail: ashok.hajare@ bharatividyapeeth.edu

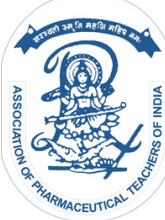

www.ijper.org 
messiness thereby causing inconvenience to the user. $^{3}$ More than $75 \%$ of all women suffer from vaginal candidiasis during their lifetime. Candida albicans is the cause of vaginal candidiasis, accounting for over $80 \%$ of the infection. ${ }^{4}$ To overcome these problems, bioadhesive drug delivery systems containing antifungal agents are being introduced. Bioadhesive polymers, polycarbophil, Hydroxy propyl methyl cellulose and polyacrylic acid are reported to be used for designing vaginal formulations. ${ }^{5}$ Various peptide and protein drugs have also been attempt to administer via the bioadhesive microparticulate vaginal delivery system. ${ }^{3}$

Ketoconazole is a weakly basic antifungal drug with poor water solubility and is widely used in the treatment of human mycotic infections and in antifungal chemotherapy. ${ }^{6,7}$ To resolve solubility problems hydrophilic polymers are used which binds to mucin or epithelial surfaces to increase the residence times of the dosage form at the absorption site. This could be useful in solving bioavailability problems resulting from a very short stay of the pharmaceutical dosage form at the absorption site. In addition, there is rather low moisture content in vagina under normal physiological conditions. ${ }^{8}$ Allium sativum L. (Liliaceae) commonly called garlic is used in modern folkloric medicine, as well as a spice for the treatment of many ailments. ${ }^{9-11}$ Garlic, has been recognized to have a potential medicinal value due to its active constituents alliin $(\sim 0.8 \%)$ and allicin $(\sim 3.7 \mathrm{mg} / \mathrm{g})$ and is used as antifungal, antibacterial, antiviral, anti-helmintic, anti-inflammatory and antiseptic. ${ }^{12}$ Moreover, reported literature indicates that garlic extracts exhibit activities against both gram negative and gram positive microbes all of which are cause of morbidity worldwide. ${ }^{13}$

The aim of the present research work was to develop a combination type bioadhesive effervescent vaginal tablet of ketoconazole and garlic for treatment against C. Albicans. To increase the dissolution of ketoconazole and garlic, effervescent disintegrants, citric acid and sodium bicarbonate were incorporated. Ketoconazolegarlic tablets were prepared using $3^{2}$ factorial design. On the basis of in-vitro drug release and swelling properties best tablet formulation was compared with a commercially available tablet for anti-fungal activity.

\section{MATERIALS AND METHODS}

Ketoconazole was kindly gifted by Cipla Ltd. (Goa, India). Garlic bulbs were purchased from the local vegetable market, whereas Candid $\AA-V 3$ tablets were purchased from local pharmacy shop. Chitosan was obtained from Molychem (Mumbai, India). Sodium bicarbonate was purchased from Finar Chemicals Ltd. (Ahmedabad, India). Citric acid anhydrous was purchased from Merck specialties Pvt. Ltd. (Mumbai, India). Hydroxy propyl methyl cellulose (HPMC K15M) was received as a gift sample from Colorcon Asia Pvt. Ltd. (Goa, India). Tulsion A-27MP was gifted by Thermax Ltd. (Pune, India). All other chemicals were of analytical reagent grade.

\section{Docking tool and algorithm}

Molecular docking was performed using VLife ${ }^{\circledR}$ MDS version 4.6 to predict probable synergistic interactions between ketoconazole and allicin (garlic). The structures of both ketoconazole and allicin were drawn in 2D and converted to 3D and optimized. The binding pocket (cavity of the CYP51A1 receptor) was first identified to dock the ligands (ketoconazole and allicin) molecules. During docking all the single bonds of residue side chains inside the defined receptor binding cavity were regarded as rotatable or flexible bonds and the ligands were allowed to rotate around all single bonds and moved flexibly within the tentative binding pocket. The structure optimization was performed using a genetic algorithm, and the best-scoring ligand-protein complexes were used for further analysis. The docking algorithm Biopredicta is based on the genetic algorithm method used to study and predict the binding mode of two compounds by optimizing their receptor-ligand binding geometry within their structures. This is a successful strategy used to search the docked conformer's space. The genetic algorithm method was performed to study and predict the binding mode of ketoconazole and allicin with the target enzyme (cavity based) cytochrome P450 lanosterol 14- $\alpha$-demethylase (PDB id: 3JUV) to prove their enhanced antifungal activity when used in combination and confirmed by their docking score. ${ }^{14,15}$

\section{Garlic powder}

Garlic bulbs were collected from local markets, weighed, peeled and cloves were cut into chips. These chips were kept in hot air oven at $58^{\circ} \mathrm{C}$ to $59^{\circ} \mathrm{C}$. The loss of moisture from garlic cloves was determined as percent weight loss per day. Maize starch was added to garlic chips (1:1) to adsorb garlic oil and to aid particle size reduction. The garlic chips were milled using a mixer grinder and screened through mesh 10 to obtain granules of uniform size. The obtained mass was further dried and screened through mesh 16 to obtain uniform sized granules. ${ }^{16}$

\section{Phytochemical screening}

Phytochemical testing of garlic powder was performed using standard procedures of analysis to determine the 
presence of alkaloids, saponins, flavonoids, carbohydrates and proteins. ${ }^{17}$

\section{Formulation optimization}

The tablet formulation of garlic and ketoconazole was optimized using $3^{2}$ full factorial design. A statistical model comprised of interactive and a polynomial term was used to evaluate the responses.

$\mathrm{Y}=\mathrm{b} 0+\mathrm{b} 1 \mathrm{X} 1+\mathrm{b} 2 \mathrm{X} 2+\mathrm{b} 12 \mathrm{X} 1 \mathrm{X} 2+\mathrm{b} 11 \mathrm{X} 12+\mathrm{b} 22 \mathrm{X} 2$

In this eq. 1, Y represents dependent variables, b0 represents the arithmetic mean response of the nine runs, and b1 represents estimated the coefficient for the factor X1. The main effects X1 and X2 represents the average results of one-factor change at a time from its low to high values. The interaction terms, X1X2, shows changes in responses when two factors simultaneously changed. The polynomial terms, X12 and X22, are included in determining non-linearity. In $3^{2}$ full factorial design, two factors were investigated, each at three different levels. The experimental trials were performed at all possible combinations. ${ }^{18}$ The dose of garlic (X1) and ketoconazole (X2) was selected as independent variables. Bioadhesion strength, $\%$ swelling and in-vitro drug release were selected as dependent variables (Y). The preparation method and characterization for tablets were kept constant for all the trials. The full factorial design layout with coded values for a dose of garlic (X1) and ketoconazole(X2) is given in Table 1.

\section{Preparation of bioadhesive vaginal tablets}

Ketoconazole, garlic, and ketoconazole-garlic bioadhesive vaginal tablets were prepared by direct compression. Single drug vaginal tablet contained $300 \mathrm{mg}$ while dose in combination tablets, varied from 200 to $400 \mathrm{mg}$. Tablets were prepared using 10-station tablet machine (minipress-1674, Rimek, India) fitted with round, flatfaced $13 \mathrm{~mm}$ punches. Compositions of combination drug tablet formulations are given in Table 2, whereas for tablets with the single drug is given in Table 3 . To obtain a homogenous blend prior to the compression particle size $<160 \mu \mathrm{m}$ was selected for all components to avoid any fractional segregation. All ingredients were mixed well with help of mortar and pestle. ${ }^{19}$

\section{Thickness and hardness}

The thickness of tablets is a function of die fill and compression force. It was determined using digital Vernier Calliper. Hardness represents the crushing strength of tablet. Hardness was determined using Monsanto hardness tester for three tablets from each batch and average values with standard deviations were recorded. ${ }^{20}$

\section{Friability}

Friability studies were performed as per USP XXVIII. Twenty tablets were weighed and placed in Roche friability, with $25 \mathrm{rpm}$ for $4 \mathrm{~min}$, tablets were dedusted and reweighed. Percent weight loss was taken as friability. Tablets with less than $1.0 \%$ weight loss from initial weight are considered acceptable. ${ }^{20}$

\section{Weight variation}

Randomly 20 tablets from each batch were selected and weighed individually. The mean weight and the percent deviation of each tablet were calculated as per USP XXVIII. $^{20}$

\section{Content uniformity}

In all two tablets from each batch were weighed and grounded in a mortar and pestle to obtain a fine powder. An amount equivalent to $400 \mathrm{mg}$ of garlic and ketoconazole was dissolved in $100 \mathrm{mM}$ acetate buffer ( $\mathrm{pH}$ 6.0) and shaken in an orbital shaker for $24 \mathrm{~h}$. The solution was filtered through Whatman filter $(42 \mu)$ and assayed spectrophotometrically (UV-VIS double beam spectrophotometer; Model Jasco V630) for ketoconazole at $221 \mathrm{~nm}$ and garlic at $262 \mathrm{~nm}$ using $100 \mathrm{mM}$ acetate buffer (pH 6.0) as blank.

\section{Tensile strength}

The tensile strength of tablet determines its compressibility. It was determined by applying pressure 0.5 to 3 tons. The prepared tablets were evaluated for thickness, hardness, and diameter. The mean yield pressure and tensile strength which indicates compressibility of tablets was calculated using Heckle software. ${ }^{22}$

\section{Swelling index}

The water absorbing capacity of a tablet is determined by its swelling behavior. ${ }^{23}$ The swelling indices of tablets were determined in $100 \mathrm{mM}$ acetate buffer ( $\mathrm{pH}$ 6.0) at $37 \pm 0.1^{\circ} \mathrm{C}$. Tablets were weighed individually; each tablet was placed separately in a $25 \mathrm{~mL}$ beaker containing $10 \mathrm{~mL}$ acetate buffer (pH 6.0) solution. The tablets were

\begin{tabular}{|c|c|c|}
\hline \multicolumn{3}{|c|}{$\begin{array}{c}\text { Table 1: Variable level of } \mathbf{3}^{2} \text { factorial design bioadhe- } \\
\text { sive vaginal tablet formulation }\end{array}$} \\
\hline Coded value & $\begin{array}{c}\text { Garlic powder } \\
\text { (mg) }\end{array}$ & $\begin{array}{c}\text { Ketoconazole } \\
\text { (mg) }\end{array}$ \\
\hline-1 & 100 & 100 \\
\hline 0 & 150 & 150 \\
\hline+1 & 200 & 200 \\
\hline
\end{tabular}




\begin{tabular}{|c|c|c|c|c|c|c|c|c|c|}
\hline $\begin{array}{c}\text { Ingredients }(\mathrm{mg}) / \text { Batch } \\
\text { codes }\end{array}$ & GK1 & GK2 & GK3 & GK4 & GK5 & GK6 & GK7 & GK8 & GK9 \\
\hline Garlic & 100 & 100 & 100 & 150 & 150 & 150 & 200 & 200 & 200 \\
\hline Ketoconazole & 100 & 150 & 200 & 100 & 150 & 200 & 100 & 150 & 200 \\
\hline HPMC K4M & 75 & 75 & 75 & 75 & 75 & 75 & 75 & 75 & 75 \\
\hline Chitosan & 75 & 75 & 75 & 75 & 75 & 75 & 75 & 75 & 75 \\
\hline $\mathrm{MCC}$ & 377.5 & 327.5 & 277.5 & 327.5 & 277.5 & 227.5 & 277.5 & 227.5 & 177.5 \\
\hline Sodium bicarbonate & 37.5 & 37.5 & 37.5 & 37.5 & 37.5 & 37.5 & 37.5 & 37.5 & 37.5 \\
\hline Citric acid & 12.5 & 12.5 & 12.5 & 12.5 & 12.5 & 12.5 & 12.5 & 12.5 & 12.5 \\
\hline Magnesium stearate & 7 & 7 & 7 & 7 & 7 & 7 & 7 & 7 & 7 \\
\hline Talc & 15 & 15 & 15 & 15 & 15 & 15 & 15 & 15 & 15 \\
\hline Tulsion A-27MP & 0.5 & 0.5 & 0.5 & 0.5 & 0.5 & 0.5 & 0.5 & 0.5 & 0.5 \\
\hline
\end{tabular}

withdrawn at 1, 2, 3, 4, 6, 8, 10 and $12 \mathrm{~h}$ and weighed. At each of these intervals, the tablet surface water was removed using a blotting paper. Swelling indices were calculated using eq. 2 .

Swelling index $(\%)=\frac{\left(\mathrm{w}_{2} \square \mathrm{w}_{1}\right)}{\mathrm{w}_{1}} \square 100$

Where, $\mathrm{w}_{1}$ is the original weight of the tablet before commencement of the test and $\mathrm{w}_{2}$ is the tablet weight at each swelling interval. ${ }^{24}$

\section{Differential scanning calorimetry}

Thermal analysis was performed to determine the synergistic interactions between garlic and ketoconazole using differential scanning calorimeter (Model TA-60, Shimadzu, Japan). Samples of garlic, ketoconazole, and optimized tablet formulation containing garlicketoconazole were analyzed by DSC. The analyses were performed on $5 \mathrm{mg}$ samples sealed in standard aluminum pans. Thermograms were obtained at a scanning rate of $20^{\circ} \mathrm{C} / \mathrm{min}$. Each sample was scanned between $0^{\circ} \mathrm{C}$ to $600^{\circ} \mathrm{C}$. The temperature of maximal excess heat capacity was defined as the phase transition temperature.

\section{Powder X-ray diffraction}

PXRD patterns of garlic, ketoconazole, and optimized combination garlic-ketoconazole tablet was recorded at room temperature on X-ray diffractometer (Philips XRD, PW 3710) with CuK $\alpha$ radiation (1.54 $\AA$ ), at $40 \mathrm{kV}$, $40 \mathrm{~mA}$ and passing through a nickel filter. The diffractometer was equipped with a $2 \mathrm{q}$ compensating slit and was calibrated for the accuracy of peak positions with a silicon pellet. Samples were mounted on a $25 \mathrm{~mm}$ holder made of polymethyl methacrylate and were subjected to $\mathrm{X}$-ray powder diffraction analysis in continuous mode with a step size of $0.01^{\circ}$ and step time of $1 \mathrm{sec}$ over an angular range of 3 to $40^{\circ} 2 \theta$. Sample holders were rotated in a plane parallel to their surface at $30 \mathrm{rpm}$ during the measurements. The XRPD patterns of samples were recorded and analyzed for any change in their nature.

\section{Ex-vivo bio adhesive strength}

Modified two arm physical balance was used to measure bioadhesive strength of tablets. Goat vaginal mucosa was stored in Krebs buffer solution at $4^{\circ} \mathrm{C}$ and used within $3 \mathrm{~h}$ of procurement. The membrane was washed first with distilled water followed by acetate buffer $\left(\mathrm{pH}\right.$ 6.0) at $37^{\circ} \mathrm{C}$. The vaginal mucosa was cut into pieces and was fixed to steel piece with cyanoacrylate adhesive and kept in the beaker. The pre-warmed acetate buffer $(\mathrm{pH} 6.0)$ at $37^{\circ} \mathrm{C}$ was added to cover the upper surface of the mucosa so as to maintain viability. The tablet was attached to the upper clamp with adhesive and the beaker was raised slowly until the substrate get close to the tablet. A preload of $50 \mathrm{~g}$ was placed on the clamp for $5 \mathrm{~min}$ (preload time) to establish adhesion. The preload was removed and water was added to the beaker at a constant rate of $100 \mathrm{drops} / \mathrm{min}$. The water addition was stopped when bioadhesive system was detached from the mucosa. The weight required to detach the system from the mucosa was noted as bioadhesive strength. The experiment was repeated 6 times with fresh mucosa in an identical manner. ${ }^{25,26}$

\section{Ex-vivo residence time}

Ex-vivo residence (ER) time in acetate buffer $(800 \mathrm{~mL}$; $\mathrm{pH} 6.0 ; 37^{\circ} \mathrm{C}$ ) was determined using modified disintegration test USP apparatus. The pieces of vaginal tissue were tied to the surface of a glass slab and vertically attached to the apparatus. The tablet was hydrated from one side of the surface with $0.5 \mathrm{~mL}$ acetate buffer $(\mathrm{pH}$ 6.0) and brought in contact with the mucosal membrane. The glass slide was fixed vertically to the apparatus and was 


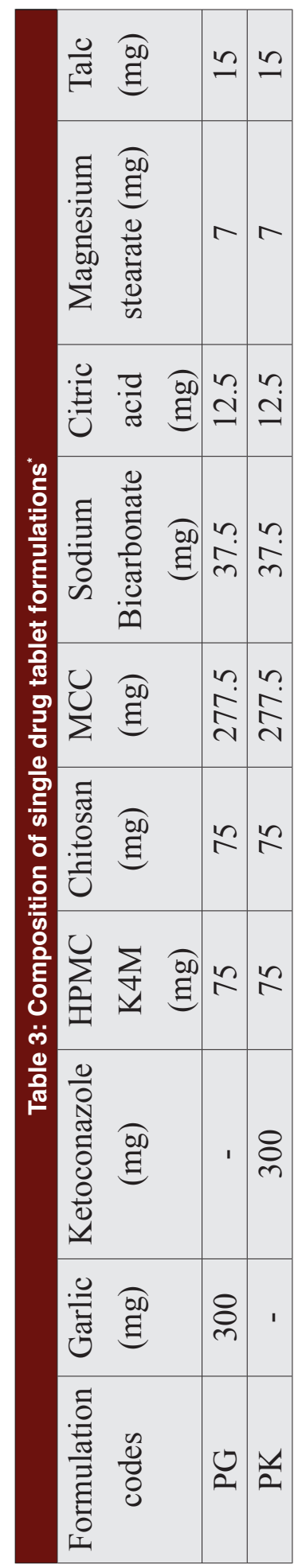

allowed to run in such way that the tablet completely immersed in the buffer solution at the lowest point and was out at the highest point. The time required for complete erosion or dislodgment of the tablet from the mucosal surface was noted. ${ }^{26}$

\section{In-vitro drug release}

The percent drug release from a garlic-ketoconazole tablet in acetate buffer $\left(900 \mathrm{~mL} ; \mathrm{pH} 6.0,37 \pm 0.5^{\circ} \mathrm{C}, 12 \mathrm{~h}\right)$ was determined using dissolution test USP apparatus with settling basket to prevent tablet floating. Test tablets were placed in basket and test was performed with stirring rate $50 \mathrm{rpm}$ and medium temperature. Accurately $5 \mathrm{ml}$ sample solution was withdrawn at predetermined time intervals and sink condition was maintained by adding an equal amount of fresh dissolution medium. These sample solutions were scanned at $221 \mathrm{~nm}$ and $262 \mathrm{~nm}$ using a Shimadzu UV-1800 UV/Vis double beam spectrophotometer. Simultaneous cumulative percentage drug release from tablets was calculated using PCP Disso ${ }^{\circledR}$ software and fitted for the best model. ${ }^{26}$

\section{Statistical analysis}

The data were expressed as a mean \pm standard deviation. Statistical analysis was performed by analysis of variance (two-way ANOVA) test for multiple comparisons formed using Design Expert ${ }^{\circledR}$ version 8.0 software. Statistical significance was set at $\mathrm{P}<0.05$.

\section{In- vitro anti-fungal activity}

The optimized tablets were tested for antifungal activity against Candida albicans ATCC 4215 (species of C. Albicans) using cup plate method. Soybean-Casein Digest Medium (SCDM) was used as media for inoculation. ${ }^{26}$ The culture was inoculated one-day prior to testing. The sterilized SCDM media and freshly grown culture of $\mathrm{C}$. Albicans were mixed aseptically under the laminar air flow and poured into sterile petri dishes. Upon solidification, cups were made in media with the help of sterile borer and lifter. The commercial tablet (Candid $\AA-V 3)$ was crushed into a powder and was dissolved in $2 \mathrm{~mL}$ of sterilized water and poured into the cups aseptically using sterile micropipette. The tablet under investigation was placed into cups filled with $2 \mathrm{~mL}$ of sterile water and kept in the refrigerator for $1 \mathrm{~h}$ followed by incubation at $28^{\circ} \mathrm{C}$ in $\mathrm{BOD}$ incubator for $48 \mathrm{~h}$. The zone of inhibition was measured to determine antifungal activity. ${ }^{19}$

\section{Accelerated stability studies}

An accelerated stability study on optimized tablet formulation was performed at $40^{\circ} \mathrm{C}(75 \pm 1 \% \mathrm{RH})$ in a stability chamber over 6 months to determine the 
change in in-vitro drug release and bioadhesive strength. ${ }^{18}$ During storage, tablet was withdrawn every month and evaluated for change in physical appearance, in-vitro percent drug release, and bioadhesive strength.

\section{RESULTS AND DISCUSSION}

\section{Docking study results for antifungal activity}

Docking studies are suitable for the predicting the metabolic behaviour of compounds through their docking into the active cavity of drug-metabolizing enzymes. It predicts the preferred orientation of one molecule into the second one, which is frequently used to forecast the binding alignment, of small drug candidates to their protein targets. The present study aims to predict the interaction between allicin and ketoconazole, into the active cavity of CYP51A1. Investigating virtual interactions between allicin and ketoconazole, (Figure. 1) allicin score was -27.68 (C4_LP8) while for ketoconazole it was 52.496346 (P2) contributing to strong interaction with ligands consuming very less energy for binding. Thus, allicin and ketoconazole exhibit strong hydrogen, hydrophobic and van der Waal interactions with the amino acid present in enzyme CYP51A1. Docking study results predicts possibility of enhanced antifungal activity of ketoconazole when combined with allicin. ${ }^{14,15}$

\section{Phytochemical constituents of garlic}

Phytochemical screening of Allium sativum shows that its extract contains alkaloids, saponins, flavonoids, carbohydrates and proteins.

\section{Formulation optimization}

The number of experiments required for optimization of the formulation is dependent on the number of independent variables selected. The response $(\mathrm{Y})$ is measured for each trial. In order to investigate factors systematically, a factorial design was employed in the present investigation. On the basis of the preliminary trials a $3^{2}$ full factorial design was employed to determine the effect of independent variables, viz. dose of garlic (X1) and ketoconazole (X2), on dependent variables as bioadhesive strength, \% swelling, and in-vitro drug release.

\section{Tablet characterization}

The physical mixture in powder form showed good compressibility thus tablets were prepared by direct compression. Tablet thickness plays a vital role in drug release from tablets. As the tablet has to be inserted into the vaginal cavity, measurement of thickness is important and thus a special care was taken to maintain a constant thickness of tablets. There were only insignificant changes in the tablet thickness. Optimized tablet thickness was suitable to be inserted into the vaginal cavity. Tensile strength obtained using Heckle software showed that mean yield pressure was less than tensile strength. The hardness of the tablet is directly proportional to the force applied to compress a tablet. To resist mechanical stress, tablets must show optimum compactness and hardness. The mean hardness of the prepared tablets ranged from 4.0- $4.3 \mathrm{~Pa}$ which can resist mechanical stress. Hardness greater than $6 \mathrm{~kg}$ would directly influence the drug release from the tablet. Mean tablet weight ranged between 787-800 $\mathrm{mg}$ complying IP mean weight variation requirements. ${ }^{22}$ Tablet formulation and production was consistent as no formulation varied by more than 5\% from the mean tablet weight. Concerning the uniformity of drug content, all formulations were acceptable. All tablet formulations showed good compactness and complied with friability specifications of USP XVIII. ${ }^{20}$

\section{Swelling studies}

Swelling is important for the assessment of adhesion. Swelling is followed by adhesion which occurs with weak bonding. In order to develop maximum adhesive strength, a polymer needs an optimum amount of water. The presence of chitosan and HPMC made tablets to exhibit good swelling ability (Figure 2). The presence of effervescent in tablets remarkably increased swelling rate and swelling capacities. Swelling phenomenon represents good disintegration due to the effect of effervescent, which increases the volume of tablet and constructs porous channels on the surface, inside of tablets. The porous channels increased the area of contact between polymer particles and water so that the polymers could be hydrated more easily. It is necessary to perform hydration studies in order to know the hydration capabilities of tablets. Initially, sharp ends of the tablet were got smoothen leaving a gel layer on the tablet. Tablets were swelled after $15 \mathrm{~min}$ and with gradual water penetration inside the tablet changed its size and integrity. All the tablet formulations, except ketoconazole tablets, showed a higher level of hydration. Tablets with garlic showed good swelling due to its good solubility in water. All tablets retained their integrity even after $24 \mathrm{~h}$. The higher concentration of ketoconazole in formulations showed the absence of erosion during swelling. There was a distinct gel layer on the surface of ketoconazole (PK) tablets. A combination drug tablet (GK8) showed higher polymer erosion due to a higher dose of garlic. ${ }^{21}$

\section{Differential scanning calorimetry}


Overlain thermograms, representing comparative state transition changes in tablets made of garlic, ketoconazole, and in the combination of garlic-ketoconazole (GK8) is shown in Figure 3. Ketoconazole tablets and garlic tablets showed melting endothermic peaks at $152.89^{\circ} \mathrm{C}$ and $330.56^{\circ} \mathrm{C}$, respectively, with no glass transition temperature. A significant shift in melting peak with a blunt shape in an optimized formulation at $159.25^{\circ} \mathrm{C}$ indicates amorphization of ketoconazole. Garlic tablets showed an endothermic peak at $300^{\circ} \mathrm{C}$ with a slight shift in its melting point from 330 indicating strong interaction with ketoconazole, a possible reason for the enhanced anti-fungal activity. Overall ketoconazole and garlic interaction helped to enhance their own antifungal activities to a greater extent.

\section{Powder X-ray diffraction}

Ketoconazole showed characteristic peaks at 3.5, 22.56, $26.50,30.45$ and $43.81^{\circ} 2 \theta$, respectively. Garlic powder being amorphous does not show any characteristic peaks. Optimized formulation (GK8) showed reduced intensity of diffraction peaks due to the interaction between drugs inducing amorphicity in ketoconazole (Figure 4).

\section{Bioadhesion}

The tablets prepared with the constant ratio of polymers and varying ratios of drugs showed good bioadhesive strength. The results of the adhesion studies showed in Figure 5 indicate an increase in bioadhesive strength with increased garlic strength. The viscous nature of garlic in water and its swelling characteristic contributed in enhanced bioadhesive strength of tablet. Bioadhesion time of tablet was appeared to be a function of a concentration of polymers and garlic, and the strength of effervescent incorporated. The tablets stay in the vagina and its retention is enhanced due viscous adhesive environment provided by polymers.

\section{In-vitro drug release}

The tablet formulations showed no initial burst release of drug within first $2 \mathrm{~h}$ but followed a gradual increment in it over $12 \mathrm{~h}$. The absence of initial burst effect could be attributed to rapid hydration and gelation of the polymers. The greater the content of the polymers in the formulations, the lower the release rate of the drug. It has been reported that HPMC in such cases is responsible for the very slow release of the drug due to build-up of an excessively viscous gel which imposes a high resistance to water penetration and erosion. ${ }^{19}$ As stated earlier, formulations prepared with polymer

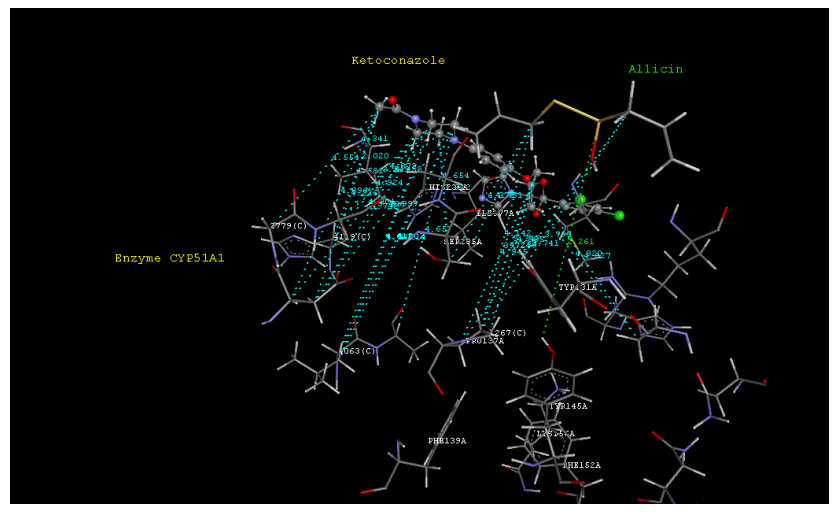

Figure 1: Co-docking of both allicin and ketoconazole into the active cavity of CYP51A1. Colour code: 1) Green: Hydrogen bonding; 2) Blue: Hydrophobic interactions.

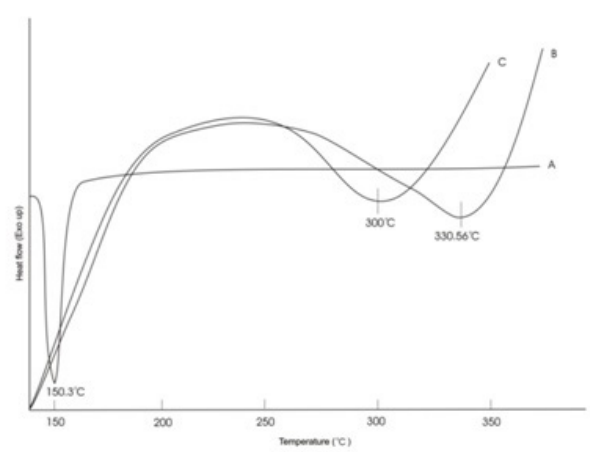

Figure 2: Overlain DSC thermogram of ketoconazole (A), garlic (B), and optimised garlic-ketoconazole tablet formulation (C).

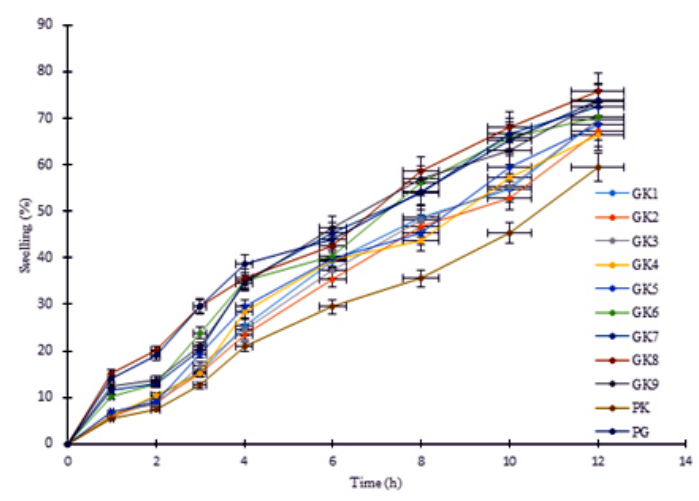

Figure 3: Comparative \% swelling of tablet formulations in $\mathrm{pH}$ 6 acetate buffer at $37^{\circ} \mathrm{C}$.

and higher concentrations of garlic showed a highly viscous gel around the tablet with higher swelling indices. The erosion rate of the swollen gel was slow compared to the rate of advancement of the swelling front into the glassy tablet core. The diffusional path length for the drug increases with time causing reduced drug release rate. The in-vitro drug release over $12 \mathrm{~h}$, presented in 
Figure 6 indicates higher drug release from formulations with higher garlic strength. On the contrary, drug release was markedly delayed in case of tablets with higher ketoconazole strength. ${ }^{27}$

The in-vitro drug release data evaluated by fitting in Korsmeyer-Peppas kinetic model shows that drug release exponent ' $n$ ' in the range of 0.45 and 0.89 indicating predominance of non-Fickian (anomalous) transport controlled by a combination of diffusion and chain relaxation mechanism. ${ }^{28}$

\section{In- vitro anti-fungal activity}

The zones of inhibition were used to investigate antifungal activities of formulations and were measured at the end of $48 \mathrm{~h}$ of incubation. The results of antifungal studies arepresentedin Figure 7. Theoptimized formulation showed an average $34.6 \pm 0.5 \mathrm{~mm}$ zones of inhibition compared to $18.4 \pm 0.4 \mathrm{~mm}, 21.6 \pm 0.5 \mathrm{~mm}$, and $25.1 \pm 0.3 \mathrm{~mm}$ of Candid V3®, PK, and PG tablets, respectively. The increased zone of inhibition of optimized tablet is indicative of its enhanced antifungal activity as a result of synergistic effect exhibited by garlic along with ketoconazole. In addition, increased activity might also be attributed due to the presence of polymers which reported to prolong the drug release and provide better contact with the wells cut in the plate. The reference tablet which turned in to the suspension was dried up with time as water was not available in the wells at the end of the study to allow diffusion of drug molecules.

\section{Stability study}

The absence of apparent change in the morphology of optimized tablets under storage indicated physical stability. At the end of stability period tablets retained more than $98 \%$ of initial actives. The in- vitro drug release was almost similar to the freshly prepared tablets. The result indicated no significant change in the properties of drug and additive.

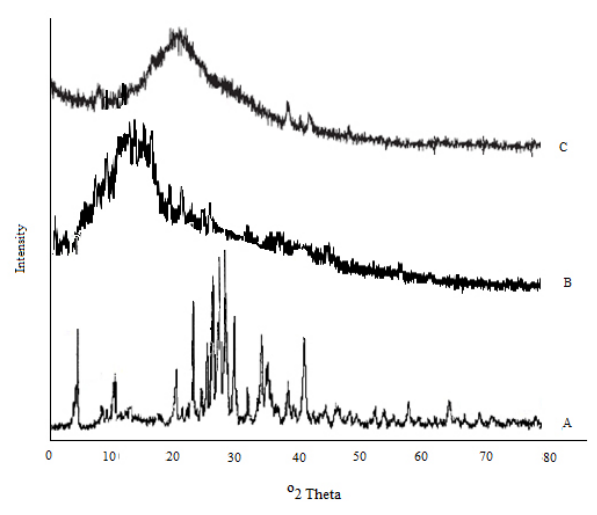

Figure 4: Overlain PXRD spectrums of ketoconazole (A), garlic powder (B) and optimised garlic-ketoconazole tablet formulations (C).

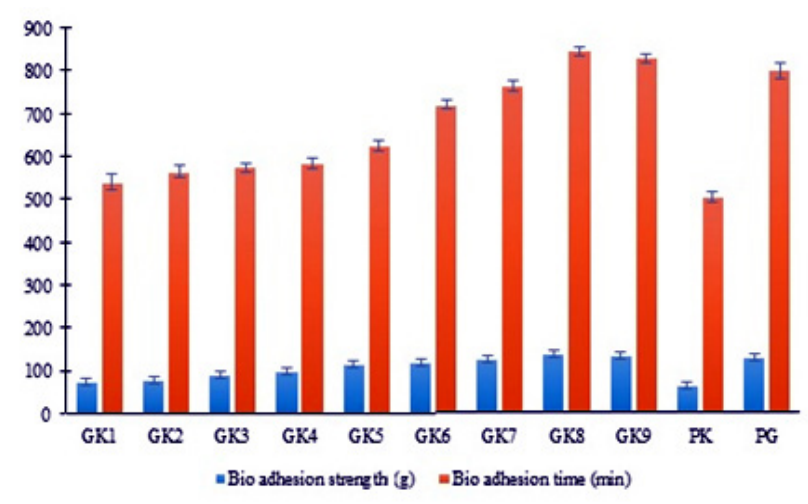

Figure 5: Bioadhesion strength and bioadhesion times of tablet formulations.

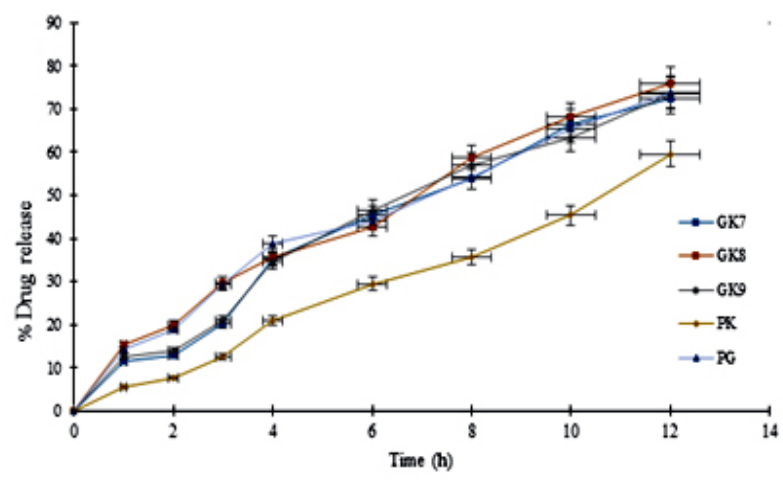

Figure 6: Drug release profile of tablet formulations (mean \pm SD, $n=3$ ).

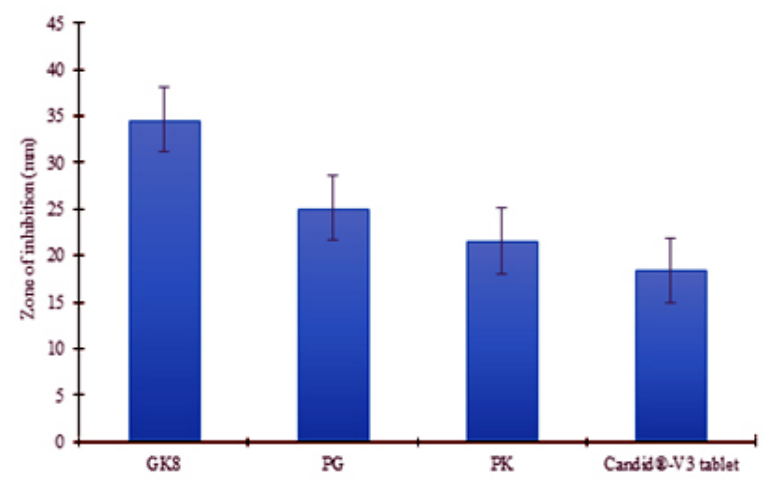

Figure 7: Comparison presentation of antimicrobial activity of tablet formulations. Error bar represent $S D(n=3)$; GK8: garlic-ketoconazole combination tablet; PG: garlic tablet and PK: ketoconazole tablet.

\section{CONCLUSION}

Docking studies used to predict the potential enhancement of antifungal activity ketoconazole when used in combination with allicin as they both are capable of interacting through strong hydrogen bonding, and hydrophobic and van der Waal interaction with CYP51A1.The directly compressed garlic-ketoconazole 
bioadhesive vaginal effervescent tablets can be prepared by direct compression for satisfactory drug release over $12 \mathrm{~h}$. Prolonged tablet retention inside the vaginal tract, consequent increase in vaginal contact time, enhanced drug release and mucoadhesion trend with the increase in garlic concentration was the net result of viscous environment exhibited. The viscous nature of mucosa contributed to a sustaining release of drug and improve therapeutic effect. There was 1.5 times increase in the anti-fungal activity probably due to the interaction between garlic and ketoconazole compare to single drug ketoconazole tablets. Full and reduced models derived for the prediction of the response variables showed satisfactory mucoadhesion and good drug release profile when $\mathrm{X} 1$ was at optimum level and $\mathrm{X} 2$ at the low level. There was significant $(\mathrm{p}<0.05)$ in-vitro antifungal activity exhibited by optimized tablet formulation. The combination of garlic with ketoconazole can be a good approach for enhancing bioadhesive, drug release and effective management of vaginal candidiasis.

\section{ACKNOWLEDGMENT}

The authors are grateful to Dr. H. N. More, Principal, Bharati Vidyapeeth College of Pharmacy, for providing necessary facilities to carry out the research work.

\section{CONFLICT OF INTEREST}

No conflict of interest are declared.

\section{ABBREVIATIONS USED}

\section{CYP51A1: Cytochrome P450 lanosterol}

14- $\alpha$-demethylase; HPMC: Hydroxy propyl methyl cellulose; PK: Plain ketoconazole tablet; PG: Plain garlic tablet; GK8: Garlic ketoconazole batch 8; SCDM: Soybean-Casein Digest Medium.

\section{REFERENCES}

1. Iyer V, Bendgude N, Poddar SS. Vaginal drug delivery. Express Pharma.2008;7.

2. Johnson VE, Masters WH. Intra-vaginal contraceptive study: Phase I Anatomy. Western Journal of Surgery, Obstetrics, and Gynaecology. 1962;70:202-7. PMid:14452114.

3. Mathiowitz E. Bioadhesive drug delivery systems: fundamentals, novel approaches, and development. New York: Marcel Dekker. 1999:563-99. https://doi.org/10.1201/b14099.

4. Richardson MD, Warnock DW. Fungal infection diagnosis and management. London: Blackwell Scientific Publications. 1993:61-73. PMid:8451742.

5. Madan J, Banode S, Dangi M. Mucosal drug delivery system. Int J Res Ayu Pharm. 2010;1(1):63-70.

6. Tawfique K, Danesment TK, Warnock DW. Clinical pharmacokinetics of ketoconazole. Clinical Pharmacology. 1988;14:13-4. https://doi. org/10.2165/00003088-198814010-00002 PMid:3280211.
7. Esclusa-D'iaz MT, Guimaraens-Mendez M, Perez-Marcos MB, Vila-Jato JL, Torres-Labandeira JJ. Characterization and in vitro dissolution behaviour of ketoconazole/and 2- hydroxypropyl-cyclodextrin inclusion compounds. Int J Pharm. 1996;143:203-10. https://doi.org/10.1016/S0378-5173(96)04704-7.

8. Karasulu HY, Taneri F, Sanal E, Guneri T, Ertan G. Sustained release bioadhesive effervescent ketoconazole microcapsules tableted for vaginal delivery. J Microencapsul. 2002;19:357-62. https://doi. org/10.1080/02652040110105382 PMid:12022501.

9. Lawson LD. Garlic: a review of its medicinal effects and indicated active compounds. Washington: American Chemical Society DC. 1998:176-209.

10. Moyers S. Garlic in health, history and world cuisine. St. Petersburg: Suncoast Press FL. 1996:1-36.

11. Thomson M, Al-Amin ZM, Al-Qattan KK, Shaban LH, Ali M. Anti-diabetic and hypolipidaemic properties of garlic (allium sativum) in streptozotocin-induced diabetic rats. Int J Diabetes Metabolism. 2007;15:108-15.

12. Lawson LD, Ransom DK, Hughes BG. Inhibition of whole blood plateletaggregation by compounds in garlic clove extracts and commercial garlic products. Thromb. Res. 1992;65:141-56. https://doi.org/10.1016/00493848(92)90234-2.

13. Deresse D. Antibacterial effect of garlic (allium sativum) on staphylococcus aureus: an in- vitro study. Asian J Med Sci. 2010;2(2):62-5.

14. Kankate RS, Gide PS, Belsare DP. Microwave assisted synthesis, antifungal evaluation and moleculer docking of benzimidazole derivatives. Der Pharma Chemica. 2014;6(6):396-405.

15. XiaoyangL, Chenming N, Chengqing L, Tao L. Drug-drug interaction prediction between ketoconazole and anti-liver cancer drug gomisin G. Afr Health Sci. 2015;15(2):590-93. https://doi.org/10.4314/ahs.v15i2.35 PMid:26124807 PMCid:PMC4480504.

16. Onyechi JOA, Chime SA, Onyishi IV, Brown SA, Eleigwe PO, Onunkwo GC. Formulation and evaluation of allium sativum tablets for improved oral delivery. Int J Pharm Sci Rev Res. 2013;22(1):6-10.

17. Sofowora, H. Screening plants for bioactive agents in medicinal plants and traditional medicine in Africa. 2nded.Nigeria: Spectrum Books. 1993;134-56

18. Patel P, Barot V, Prajapati B, Rajesh KS, Jha L. Preparation and evaluation of effervescent bioadhesive vaginal tablet of itraconazole for vaginal candidiasis. Pharmagene. 2013;1(1):1-6.

19. Bhat SR and Shivakumar HG. Bioadhesive controlled release clotrimazole vaginal tablets. Trop J Pharm Res. 2010;9(4):339-46. https://doi.org/10.4314/ tjpr.v9i4.58924.

20. United States Pharmacopeia XXVIII, National Formulary XXIII. Rockville: United States Pharmacopeial Convention. 2005;2745. PMCid:PMC1305370.

21. Jafar A, Reza E, Majid $S$ and Massoud S. Influence of hydroxypropyl methylcellulose molecular weight grade on water uptake, erosion and drug release properties of diclofenac sodium matrix tablets. Trop J Pharm Res. 2011;10(5):535-41.

22. Pitt KG and Heasley MG. Determination of the tensile strength of elongated tablets. Powder technol. 2013;238:169-75. https://doi.org/10.1016/j. powtec.2011.12.060.

23. Patel $G$ and Patel A. A novel effervescent bioadhesive vaginal tablet of ketoconazole: formulation and in-vitro evaluation. Int $\mathrm{J}$ Pharm Tech Res. 2010;2:656-67.

24. Patel $\mathrm{G}$ and Patel $\mathrm{M}$. Compressed matrix dual component vaginal drug delivery system containing metoclopramide hydrochloride. Acta Pharm. 2009;59:273-88. https://doi.org/10.2478/v10007-009-0029-4 PMid:19819824.

25. Ghosh A, Shah A, Das S, Ghosh T. Studies on formulations and design of zidovudine loaded particulate vaginal bioadhesive tablet. Int J Pharm Tech Res. 2011;3:82-92.

26. Karasulu HY, Himilgou S, Matein D, Guneri T. Efficacy of new ketoconazole bioadhesive vaginal tablet on candida albicans. Farmaco. 2004;59(2):163-7. https://doi.org/10.1016/j.farmac.2003.11.018 PMid:14871509.

27. Baveja SK, Rao KVR, Devi KP. Zero-order release hydrophilic matrix tablets of $\beta$-adrenergic blockers. Int J Pharm. 1987;39:39-45. https://doi. org/10.1016/0378-5173(87)90196-7.

28. Paulo C, Jose MS. Model lingand comparison of dissolution profiles. Euro J Pharm Sci. 2001;13:123-33. https://doi.org/10.1016/S0928-0987(01)00095-1. 


\section{PICTORIAL ABSTRACT}

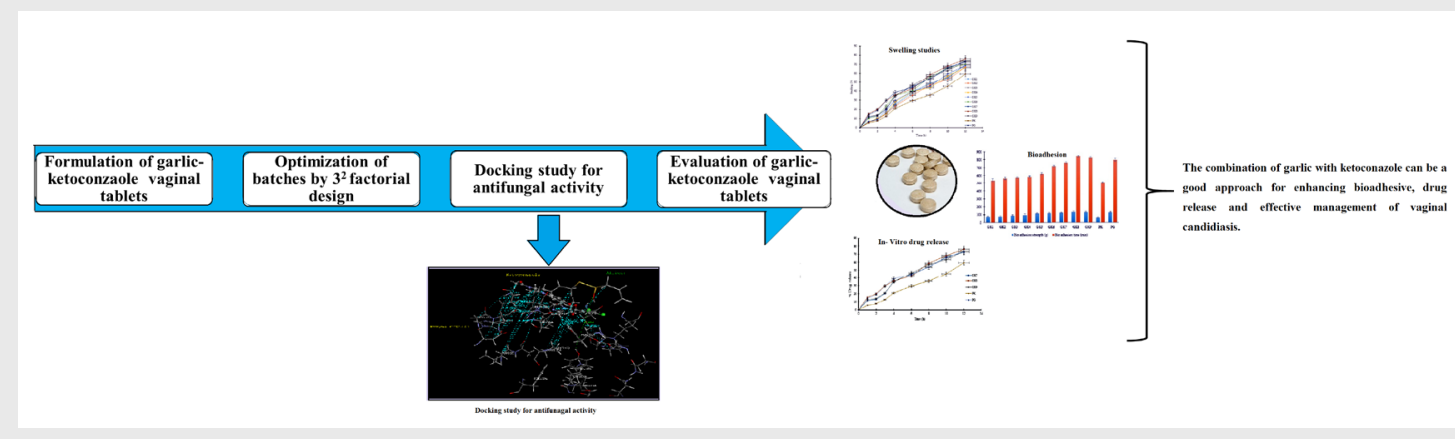

\section{SUMMARY}

- Bioadhesive garlic- ketoconazole vaginal tablets was prepared by direct compression to treat candidiasis.

- Docking study predicts possibility of enhanced antifungal activity of ketoconazole when combined with allicin (garlic), due to their synergistic interactions.

- The tablet formulation of garlic and ketoconazole was optimized using $3^{2}$ full factorial design. The dose of garlic (X1) and ketoconazole (X2) was selected as independent variables, whereas bioadhesion strength, \% swelling and in-vitro drug release were selected as dependent variables (Y).

- The presence of chitosan and HPMC made tablets to exhibit good swelling ability, with increased swelling rate and swelling capacities. Swelling represents good disintegration due to the effect of effervescent, which increases the volume of tablet and constructs porous channels on the surface.

- Increased garlic strength increases bioadhesive strength of tablet which helps it to stay in the vagina for longer drug release and its retention is enhanced due viscous adhesive environment provided by polymers.

- The tablet formulations showed no initial burst release of drug within first $2 \mathrm{~h}$ but followed a gradual increment in it over $12 \mathrm{~h}$.

- The increased zone of inhibition of optimized tablet is indicative of its enhanced antifungal activity as a result of synergistic effect exhibited by garlic along with ketoconazole.

- Stability studies indicates, tablets retained more than $98 \%$ of initial actives.

\section{About Authors}

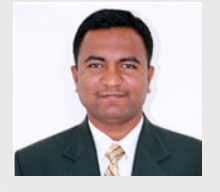

Dr. Ashok A. Hajare: Professor, Department of Pharmaceutics, Bharati Vidyapeeth College of Pharmacy, Kolhapur, Maharashtra, INDIA.

Cite this article: Powar TA, Hajare AA, Patil-Vibhute PB, Nadaf SJ, Jarag RJ. Bioadhesive Garlic and Ketoconazole Vaginal Tablets for Treatment of Candidiasis. Indian J of Pharmaceutical Education and Research. 2017;51(2):239-48. 